\title{
LA MIRADA PINTORESCA
}

\author{
Javier Maderuelo \\ Universidad de Alcalá
}

\section{RESUMEN}

Se pretende mostrar lo pintoresco no como un estilo artístico ni como una característica de ciertos objetos, sino como la forma intelectual bajo la cual los británicos entendieron el mundo, el territorio, el paisaje y la ciudad, durante la centuria que abarca entre 1730 y 1830. En la segunda mitad del siglo XVIII la transformación del territorio se convirtió en algo más que una moda o una distracción rural, se convirtió en una de las artes mayores. Este arte cobró un nombre: jardinería paisajista y desde Gran Bretaña se extendió a Europa y América. Al ser considerado arte, la jardinería paisajista desarrolló unas categorías estéticas, unos principios poéticos y unos preceptos teóricos que entretuvieron a filósofos, poetas y eruditos durante más de cien años, con un nivel de producción intelectual y editorial sorprendente. La categoría estética más característica fue lo pintoresco, teorizada por William Gilpin, Richard Payne Knight y Uvedale Price.

Palabras clave: Paisaje, pintoresco, estética, historiografía.

\section{ABSTRACT}

It is the purpose of this paper to present the picturesque not as an artistic style or a characteristic of certain objects, but as the intellectual means by which the British understood the world, land, landscapes and the city in the period between 1730 and 1830. In the second half of the 18th century the transformation of landscapes became more than just a fashion or rural pastime, emerging as one of the highest art forms and acquiring a name of its own in "landscape gardening", which spread from Great Britain to Europe and America. Considered an art form in its own right, landscape gardening developed its own aesthetic categories, poetic principles and theoretical premises, which occupied the minds of philosophers, poets and scholars alike for more than 100 years, resulting in a surprising amount of intellectual considerations and publications. Its most representative aesthetic field was the picturesque, the principles of which were expounded by William Gilpin, Richard Payne Knight and Uvedale Price.

Keywords: landscape, picturesque, aesthetic, historiography.

La historiografía del arte encontró en la noción de estilo una potente herramienta para ordenar las obras y establecer la secuencia de prelaciones temporales que permite, atendiendo a sus particularidades formales, establecer la sucesión de estas, situando una antes o después que otras, en una especie de asimilación de las teorías evolucionistas desarrolladas por la ciencia. Así, al románico, con sus pequeños arcos de medio punto, le sucede el gótico, con sus grandes ojivas, y a éste el Renacimiento, con sus esbeltas columnas y amplios arcos de medio punto, y después el barroco, con sus columnas y pilastras pareadas y sus fachadas desenfiladas, como si existiera una especie de ley biológica que conduce de una manera 'natural' de unas formas a otras. Por supuesto, en cada país la evolución de las formas artísticas ha llevado un ritmo distinto y se ha servido de diferentes formas y soluciones en atención a sus particularidades ideológicas, políticas o económicas, al igual que los animales y las plantas se diferencian en cada región del planeta como consecuencia de las diferencias ambientales, lo que afianza el símil biológico de la historia. Sin embargo, hay un momento en la historia de Europa a partir del 
cual esa artificiosa sucesión de estilos, que para los padres de la historiografía del arte tan claramente se habían sucedido, se trunca y se difracta de manera que cuando se pretende explicar lo que ha sucedido en el arte europeo durante el siglo XIX el concepto de estilo, como expresión de una época, hace agua y a cambio aparecen movimientos (atención al significado de algo inestable) que no se refieren a aspectos formales o al menos a formas claramente reconocibles, como lo son los arcos o la maneras de jerarquizar los elementos de una composición pictórica, sino a intenciones, voluntades y sensibilidades, calificadas como romanticismo, idealismo, naturalismo o pintoresco. Nociones que escapan a lo meramente morfológico para hundir sus raíces en lo ideológico.

Así, en muchos casos, lo pintoresco aparece como una cualidad de los objetos y de las obras de arte, pero esa cualidad parece exceder lo meramente formal o incluso ser solo un adjetivo a añadir a un supuesto estilo con el fin de matizar algún aspecto particular o peyorativo.

Los estilos han resultado ser categorías útiles para las grandes generalizaciones, para los esquemas didácticos de carácter divulgativo, pero cuando se pretende aplicar a una región, un artista o una obra concreta esa noción se torna inoperante y, si llega al caso, confunde más que ayuda a comprender. Por eso, no parece que hablemos con propiedad si utilizamos el término Renacimiento al referirnos al arte inglés, ya que los artistas de aquel país no imitaron las formas romanas ya que no sintieron la necesidad de recuperar o renacer a algo que antes no hubieran tenido, de la misma manera que la palabra gótico no tiene en Inglaterra el mismo sentido que cobra en Francia o en España, no solo porque, en cuanto estilo, se extiende desde la Edad Media hasta nuestros días, sino porque adquiere en Inglaterra un carácter ideológico de corte nacionalista e identitario que no posee en el resto de los países europeos.

Esta introducción sobre la noción de estilo en la historiografía es necesaria para entender el sentido que posee el término pintoresco en la historia del arte, tanto cuando se pretende introducir como carácter estilístico o cuando se pretende utilizar como adjetivo que predica una cualidad. En otros artículos y libros ${ }^{1}$ se ha tratado con solvencia y profundidad sobre las definiciones y el sentido de lo pintoresco como categoría estética, por lo que no voy a resumir ni caricaturizar aquí lo que en otros lugares ha sido tratado y explicado con autoridad y extensión, pero si me parece que merece la pena ahora contemplar algunos aspectos del arte separándolos de la noción de estilo para observarlos a la luz de lo pintoresco. Se trata de mostrar lo pintoresco no como un estilo artístico sino como la forma intelectual bajo la cual los británicos entendieron el mundo, el territorio, el paisaje y la ciudad.

Lo pintoresco surgió como consecuencia de una serie de ideas filosóficas, políticas y artísticas, que implicaron a la poesía, la pintura, la arquitectura, la novela y la jardinería, artes desde las que se reclamaban unos cauces para forjar una nueva sensibilidad que terminó configurando un marco cultural más amplio, que conocemos en el ámbito europeo con el nombre de la llustración.

La revolución de 1688, que fundó el régimen parlamentario en Gran Bretaña, hizo posible que surgiera una corriente de pensamiento crítico y que se fomentaran las discusiones teóricas que dieron origen a una serie de proposiciones filosóficas conocidas bajo el título genérico de "empirismo inglés" 2 . Los filósofos empiristas se empezaron a interesar por algunos problemas prácticos, relacionados con la mejora moral del individuo, dejando de lado otros temas de carácter meramente especulativo, como la metafísica, intentando situar a la filosofía en el mundo de los asuntos reales, entre ellos los análisis del gusto $^{3}$ y la sensibilidad que darán origen a la estética inglesa.

Las ideas desarrolladas por el empirismo inglés sobre la importancia del pensamiento analítico en el conocimiento, es decir, sobre la experiencia de los sentidos como fuente de conocimiento, permitió el nacimiento de las ideas estéticas en Inglaterra. Estas ideas tuvieron su marco en la denominada "teoría del gusto", cuyos iniciadores fueron el crítico literario Joseph Addison, quien destacó los aspectos individuales y empíricos que concurren en el gusto, y el filósofo Anthony Ashley Cooper, 3er conde de Shaftesbury, introductor de la idea de moral sense, a 
través de la cual se puede aprehender la belleza de la naturaleza y del arte.

En el seno de esa teoría del gusto elaborada por Addison se sitúan las indagaciones filosóficas sobre lo bello y lo sublime, enunciadas por Edmund Burke en 1759, y los Tres ensayos sobre la belleza pintoresca de William Gilpin, de 1792, ampliados con la discusión mantenida entre Richard Payne Knight y Uvedale Price, que abarcaron toda esa década de final de siglo, y con los manuales de jardinería paisajista publicados por Humphry Repton.

\section{$\star \star$}

El término picturesque apareció en inglés para expresar los efectos cromáticos y lumínicos que algunos viajeros del grand tour descubrían en los cuadros de pintores sensualistas venecianos, como Giorgione o Tiziano. Para el viajero inglés de finales del XVII la novedad que presentaban esos pintores radica en los cambios de luminosidad y en los fenómenos ambientales que se muestran en sus fondos paisajísticos de sus pinturas. Pero, la naturaleza y el paisaje se empezaron a apreciar en los cuadros, a través de la obra de Nicolas Poussin, Gaspard Dughet, Salvatore Rosa y, sobre todo, de Claudio de Lorena, quienes habían representado como fondos de sus escenas supuestamente históricas paisajes arcádicos, inspirados en la campiña romana (Fig. 1). De aquí la estrecha relación del término pintoresco con el paisaje, pero el camino que conduce del disfrute en la contemplación de la pintura a la valoración estética de las cualidades del territorio no fue ni inmediato ni directo.

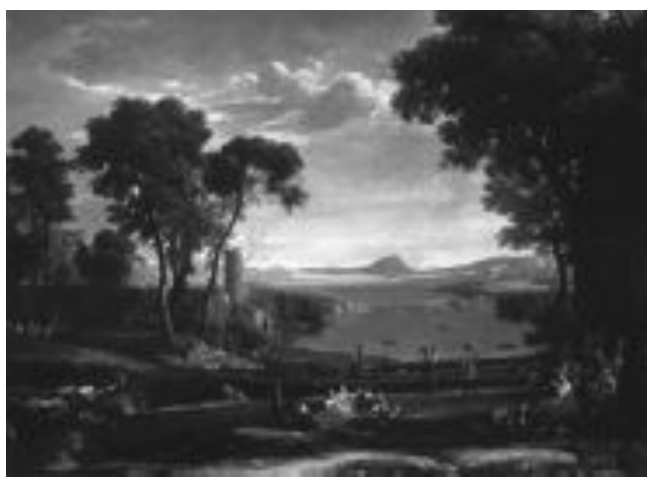

Fig. 1. Claudio de Lorena: Paisaje con figura bailando (Matrimonio de Isaac y Rebeca), 1648. National Gallery, Londres.
Leon Battista Alberti, apoyándose en la autoridad de Plinio y Vitruvio, en su tratado Sobre la pintura, asegura que la fuente de todo cuadro debe estar en la poesía clásica, aconsejando a los pintores que lean a los poetas ${ }^{4}$. La pintura, que según la máxima horaciana "Ut pictura poesis" imita a la poesía, era entendida como el arte de componer historias, tal como argumenta Leonardo da Vinci en su Tratado de pintura, donde reivindica que la pintura no se hace solo con pigmentos, aplicando delicados colores que generan imágenes, sino que el arte reside en la capacidad que tiene el pintor para mostrar sucesos o para narrar historias que son transcendentes, como lo hace la poesía e incluso mejor que ella ${ }^{5}$. Así pues, la pintura Occidental, desde el Renacimiento, se apoya en la poesía, en la narración poética.

El arte del pintor reside en la eficacia que posea para plasmar una historia por medio de imágenes sirviéndose de los recursos iconográficos. De manera que la mayor parte de la narración pictórica reposa en las figuras que quedan caracterizadas por la posición que ocupan en el cuadro, los gestos que las caracterizan, los colores de sus ropajes y las convenciones iconológicas que les hacen reconocibles.

Los buenos pintores tomaron de los poetas no solo el tema de la historia y los detalles narrativos sino también supieron apreciar la capacidad que algunos de ellos tenían para generar 'imágenes retóricas', para inventar situaciones o describir ambientes. El conocimiento, desde el siglo $\mathrm{XVI}$, de algunos tratados de retórica y gramática que hablan de la excelencia del discurso, ofreciendo fórmulas para conseguir la perfección, la elevación, la nobleza y la composición ${ }^{6}$ animaron a los pintores a abandonar los esquemas compositivos heredados de los talleres artesanales para conseguir un 'estilo' característico, una 'maniera' basada en innovaciones como la naturalidad de las figuras, la fidelidad en la representación de los ropajes, la profundidad de las escenas, la variedad del colorido, el modelado de las figuras o el riesgo en la presentación de escorzos. En cualquier caso, lo importante era conseguir una buena definición de las figuras en las que descansaba no solo la veracidad del tema sino el carácter moral de la historia que se transmitía. 
Tal vez por esa razón llamó la atención en Roma la presencia de algunos pintores extranjeros, que venían del norte: de Flandes, de Picardía, de Lorena y que reducen en el lienzo la importancia de la 'historia' que narran, minimizando el tamaño de los personajes, en beneficio de algunos detalles retóricos, como la calidad de la luz, la profundidad de campo, la definición de los "lejos" o de algunos elementos complementarios y marginales, como las ruinas o los árboles que ambientan la escena, que van cobrando paulatinamente tanta importancia como las figuras de la historia que supuestamente deben presentar. Me estoy refiriendo a la obra de pintores como Claudio de Lorena, Nicolas Poussin, Gaspard Duguet y, posteriormente, Jan Frans van Bloemer (apodado significativamente Orizzonte), que se habían afincado en Roma en el momento de la apoteosis del barroco, dominado por el espíritu de la contrarreforma y la exaltación de la virtudes de los nuevos santos fundadores de las órdenes religiosas ${ }^{7}$, a los que se están dedicando entonces innumerables iglesias, frescos, estatuas y cuadros.

Para unos viajeros anglicanos, nostálgicos y sentimentales, que no están interesados en la apoteosis de las figuras de la contrarreforma católica, los temas religiosos que tratan los pintores italianos carecen de interés. No es, por tanto, extraño que se fijen no solo en la obra de los pintores extranjeros que viven en Roma sino en otras cualidades diferentes de la historia sobre la que supuestamente tratan los cuadros.

El aprecio del paisaje y las cualidades paisajistas en Inglaterra surgió, en buena medida, como consecuencia de las experiencias acumuladas durante el grand tour. El viajero, al recorrer, por puro placer y sin que medie necesidad, diversos territorios muy diferentes de los de su país de origen, como el incómodo y esforzado paso de los Alpes, los serenos valles supuestamente clasicistas de la campiña romana, las agradables costas mediterráneas o la terrible presencia del Vesubio, percibían las diferencias, no solo en las formas geográficas sino en los cambiantes matices de la luz, en las cualidades del color local y en el ambiente, efectos que después intentaban reconocer en cierto tipo de pintura. De esta manera se puso de moda entre la aristocracia inglesa coleccionar cuadros que les permitieran recordar idealizadamente los lugares que habían visitado. Pero, desgraciadamente, no existían en Italia, a finales del siglo XVII pintores que realizaran vistas de lugares, como en los Países Bajos, por lo que tuvieron que recurrir a coleccionar cuadros de Claudio y de los Poussin ${ }^{8}$, quienes, junto con Salvatore Rosa, se convirtieron en los 'modelos' del paisaje.

Pero la apreciación del paisaje no fue ni directa ni inmediata. El interés por la naturaleza y por el paisaje en Gran Bretaña comenzó con la obra de poetas como James Thomson, John Dyer, Thomas Gray y William Shenstone', quienes iniciaron lo que se ha llamado la 'Edad del paisaje ${ }^{10}$. Ellos se fijaron en los valores paisajistas de la obra de los pintores mencionados y desde ella dirigieron el entusiasmo hacia el aprecio por la naturaleza, consiguiendo que los lectores de sus poemas empezaran a mirar el paisaje real con ojos de pintor. Hasta entonces, los viajeros miraban el campo intentando disfrutar de su amenidad, descubrir su significado histórico o apreciar su rentabilidad económica, Thomson, Dyer, Gray y Shenstone les enseñaron a mirarlo como si estuvieran contemplando pinturas paisajistas.

El enfoque pictórico de estos poetas resultó ser algo nuevo en poesía, ya que invirtieron el sentido de las relaciones entre las artes. Los pintores, tal como recomendaban Alberti y Leonardo, se inspiraban en la obra de poetas como Ovidio o Virgilio para componer sus cuadros, mientras que los poetas de lo pintoresco se inspiraban en las obras de los pintores para componer sus poemas, proyectando la sensibilidad pictórica hacia la realidad.

Pero en esta actitud había algo más que un mero traspaso de valores pictóricos y poéticos. Comenta al respecto Christopher Hussey:

Poesía, jardinería, arquitectura y pintura, e incluso la arqueología, siempre que tenían que trabajar de alguna manera con el campo, abandonaban su aislamiento como artes separadas y se reunían en un único 'Arte del paisaje' gracias al punto de vista pintoresco. El jardinero canta en (una especie de) poesía sus esfuerzos por copiar a los pintores; 
el arquitecto diseña los edificios que un pintor podría haber delineado al expresar una idea poética. El pintor ilustra los episodios de los poetas con paisajes que un jardinero gustosamente habría hecho propios. Esta fusión de las artes al calor del entusiasmo por la naturaleza, tal como la habían mostrado los pintores, es el mayor logro de lo pintoresco. ${ }^{11}$

En este contexto, merece la pena nombrar a William Shenstone, autor de un jardín llamado Leasowes, que empezó a construir hacia $1745^{12}$. George Saintsbury calificó a Shenstone de maestro del "estilo artificialmente natural en poesía"13, y el jardín de Leasowes resultó ser su poema más elaborado (Fig. 2). En él, el arte se puso al servicio de la naturaleza. El poeta se complacía mostrando su jardín y comprobando los efectos que producía en sus visitantes que quedaban admirados ante las imágenes poéticas que iban apareciendo a lo largo del recorrido por un camino que circundaba la finca abriendo vistas selectivas hacia elegidos puntos concretos situados en el interior. Richard Graves, en su deliciosa novela titulada Columella, ${ }^{14}$ teje la trama en torno a este jardín y a la figura, ligeramente satirizada, de su propietario.

No todas las mentes sensibles de Gran Bretaña pertenecían a la nobleza ni poseían suficiente fortuna como para afrontar el grand tour por Europa o construir un jardín pintoresco. El reverendo William Gilpin, que pertenecía a este grupo de eruditos carentes de suficiente fortuna,

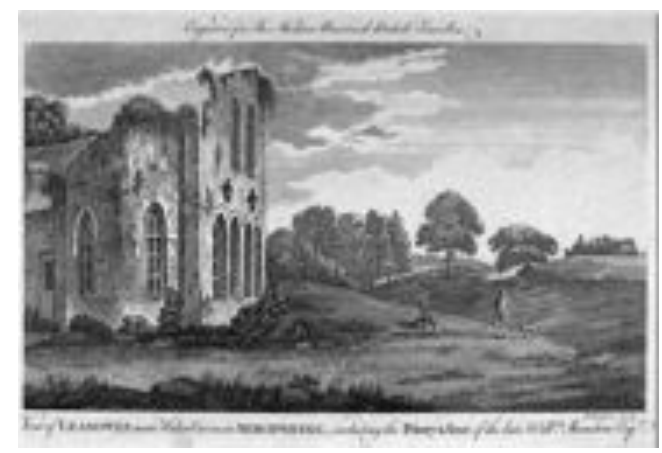

Fig. 2. Vista de Leasowes. Grabado de D. Jenkins, publicado en Modern Universal British Traveller, 1811. se planteó realizar otro tipo de viajes, eligiendo para ello las agrestes campiñas del sur de Gales, muy particularmente el valle del río Wye, en el que encontró no solo vistas paisajistas sino ruinas históricas, como la abadía gótica de Tintern, que describirá e ilustrará en sus libros. Animado por las buenas críticas del poeta Thomas Gray y contando con el apoyo de William Mason, ${ }^{15}$ se decidió a publicar en 1782 sus Observations on the River Wye and several parts of South Wales. A este ensayo seguirán dos narraciones de viajes, ilustradas con acuarelas, Tour in the mountains and lakes of Cumberland and Westmoreland (1789) y Tour in the highlands of Scotland (1789) que tuvieron un gran éxito y fueron traducidas al francés y al alemán.

William Gilpin era no solo un consumado acuarelista sino un hábil grabador que ilustra-

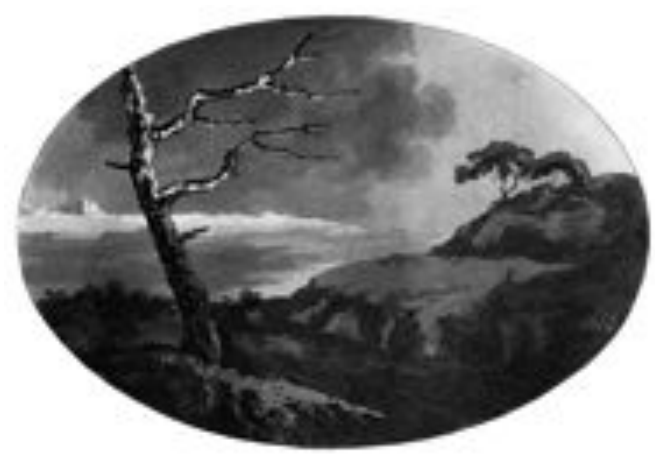

Fig. 3. William Gilpin: Forest scenary. Grabado editado en 1808.

ba sus libros con aguatintas ejecutadas por él, lo que le permitió hacer aún más presentes al lector los efectos visuales de aquellos paisajes cuyas bellezas naturales detallaba (Fig. 3). Con sus libros muchos viajeros ingleses aprendieron a descubrir las cualidades que posee la naturaleza hasta en los elementos más casuales, en los cambios de luz y sombra, en las distintas estaciones y en las irregularidades de la vegetación más modesta.

El libro de Gilpin dedicado al valle del río Wye hizo popular esta región del sur del Gales que empezó a ser visitada por un número creciente de turistas en busca de las ruinas góticas que se describen en él, llamando la atención de escritores, como John Keats o Walter Scott y muy 
concretamente de los pintores Thomas Hearne, William Day, Thomas Girtin, Michael Angello Rooker, John 'Warwick' Smith, Loutherbourg y William Turner quienes, siguiendo los libros y descripciones de Gilpin, recorrieron las rutas del sur de Gales y del río Wye dibujando, grabando y pintando cuadros de sus riberas, castillos y ruinas, como las vistas de la abadía de Tintern (Fig. 4).

La estética de los sentimientos, implícita en las teorías de Edmund Burke sobre lo bello y lo sublime ${ }^{16}$, y en las de lo pintoresco de Gilpin, Knight y Price, dieron origen al romanticismo y a un cierto tipo de jardinería que pretendía provocar efectos sensibles inmediatos por medio de imágenes paisajistas formadas por cuadros naturales, tal como sugería Thomas Whately en sus Observations on Modern Gardening, libro publicado en Londres en $1770^{17}$.

William Gilpin fue el inventor del término 'belleza pintoresca', utilizado para calificar aquellos objetos que sin cumplir las normas de la be-

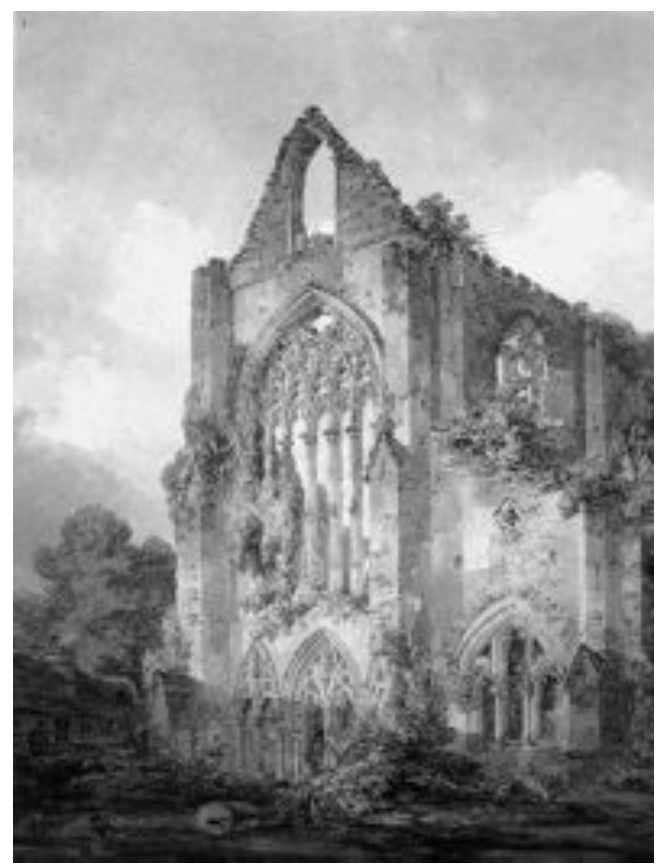

Fig. 4. Joseph Mallord William Turner, Tintern Abbey, 1793. Tate Gallery, Londres. lleza clásica eran adecuados para ser pintados. En sus Three Essays ${ }^{18}$, Gilpin pretendió mostrar las características físicas de lo pintoresco como opuestas a las de lo bello y lo sublime, señalando que las cualidades propias de lo pintoresco son lo áspero, lo rugoso, lo hirsuto y lo tosco. Por su parte, Uvedale Price, en Essays on the Picturesque, propuso lo pintoresco como una auténtica categoría que habría que situar a la misma altura que lo bello y lo sublime ${ }^{19}$, en este sentido Richard Payne Knight coincide con Price en su Didactical Poem ${ }^{20}$, pero ambos, junto con Humphry Repton, se enzarzaron en una discusión pública ${ }^{21}$ sobre infinidad de detalles que pretendió ser zanjada por Knight con la publicación de su An Analytical Inquiry into the Principles of Taste, ${ }^{22}$ libro en el que desarrolla minuciosamente una extensa teoría que abarca todos los sentidos y las artes; la percepción, la imaginación, el juicio y las pasiones; y categorías como lo sublime, lo patético, lo ridículo y lo novedoso, mientras que sir Uvedale Price, siguiendo el método indagatorio de Burke, desarrolló una descripción de los placeres derivados de lo pintoresco.

Tal vez el personaje que mejor supo interpretar esta estética sentimental fue Lancelot Brown, apodado "Capability Brown", quien comenzó como jardinero en Stowe (Fig. 5), en 1741, donde continuó la obra de William Kent, de quién tomó la idea de agrupar los árboles ${ }^{23}$, que colocaba formando islas sobre amplias praderas, así como la de naturalizar los bordes de los estanques, haciéndolos parecer lagos. Se le puede conceder el honor de ser el primer profesional del 'jardín paisajista' ya que, durante su vida intervino en doscientos once jardines, de tal manera que se puede considerar obra suya la transformación de la Inglaterra central y meridional en un continuo parque, que pasa de la finca de un vecino a la del otro ${ }^{24}$. Brown intentó siempre transformar el campo en pinturas tridimensionales, sin embargo, sus 'capacidades' no debieron ser tan grandes como él suponía y su trabajo ha sido muy criticado, incluso por los defensores del estilo pintoresco.

La filosofía empirista, la actividad parlamentaria y el sentido de la economía que regía el pensamiento inglés condujo no solo a una apreciación estética del campo, en el que los terrate- 


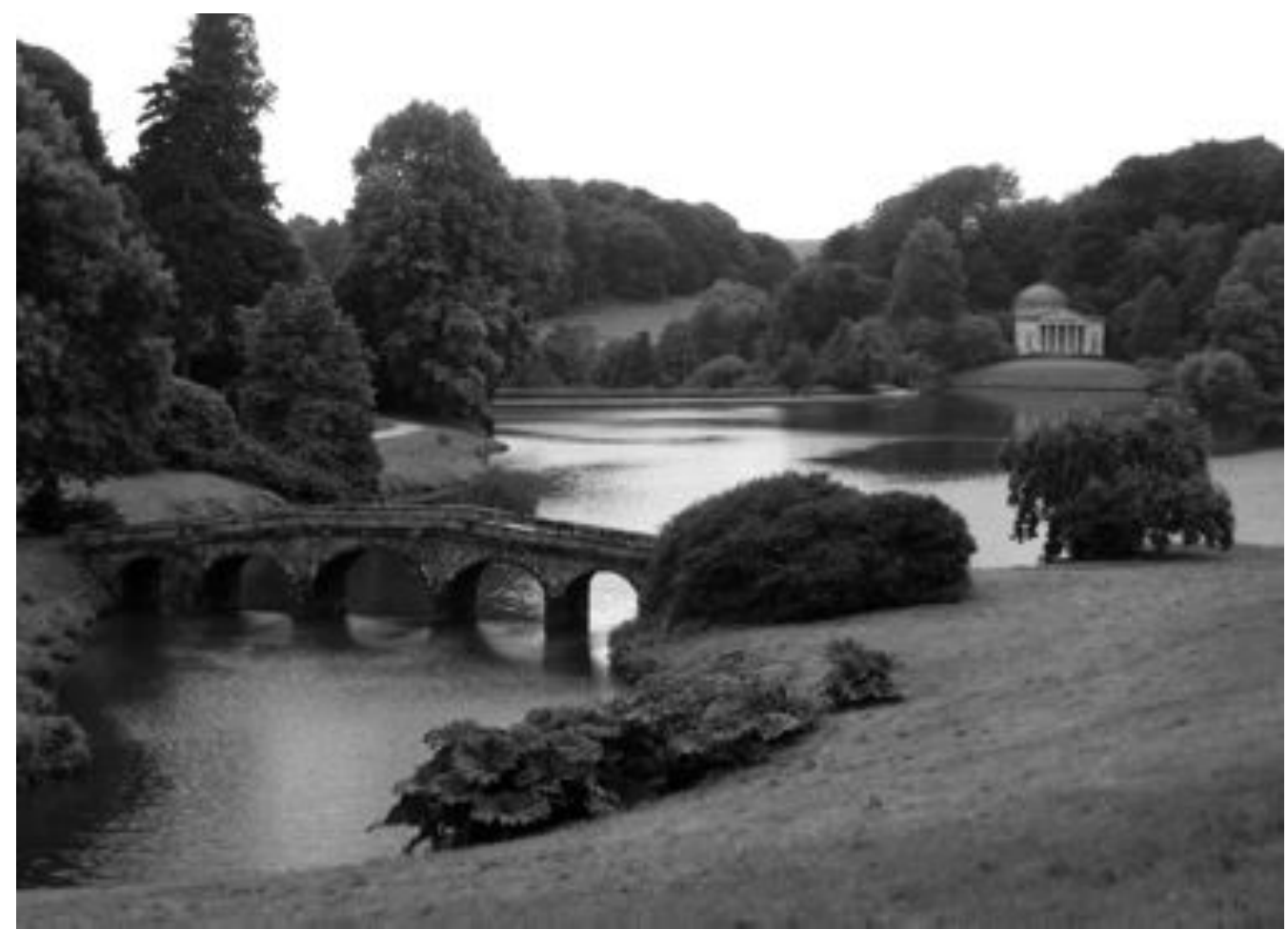

Fig. 5. Vista de Stowe con los crumps de Capability Brown.

nientes podían descubrir contrastes de colores y juegos de luces y sombras, así como disfrutar de la tranquilidad de una vida sin etiquetas, alejados de los ajetreos y las intrigas de la ciudad, sino a otro tipo de disfrute que adquirirá un sentido moral: la satisfacción de sentirse propietario, de ejercer plena y responsablemente la propiedad. Cada terrateniente que se precie debe cuidar y engrandecer el trozo de Inglaterra del que es propietario, reproduciendo en él sus ideales políticos y sociales de país.

En 1712 Joseph Addison, en la revista The Spectator se preguntaba: "por qué no transformar con plantaciones frecuentes todo el país convirtiéndolo en una especie de jardín. Todos podrían hacer que sus posesiones fueran un bonito paisaje" 25 . Esta idea se tomó al pie de la letra y muchos terratenientes, ayudados de personajes como Capability Brown o Humphry Repton, mejoraron sus posesiones ajardinándolas, para ello talaron bosques, plantaron árboles formando grupos, abrieron prados, rectificaron laderas, embalsaron arroyos y construyeron falsas ruinas, intentando siempre que las transformaciones parecieran naturales a los ojos del visitante, de manera que las fincas pudieran ser tan pintorescas como productivas. Christopher Hussey comenta: "Hacer del paisaje un jardín privó durante el siglo XVIII de deliciosos parterres a muchos propietarios. Pero el ajardinamiento del paisaje le dio a la nación su particular campiña"26.

Capability Brown, primero, y Humphry Repton, después, generaron un estilo de mejora paisajista que se convirtió en modelo y en patrón, y que llegó a caracterizar la campiña inglesa, incluso en la actualidad. Repton partió de la teoría de lo pintoresco, pero la redujo a un método de trabajo práctico. El catálogo de sus obras realizadas entre 1788 y 1816, elaborado dos años antes de su muerte, recoge más de cien transformaciones de parques y jardines. En sus red books, carpetas encuadernadas en rojo en las que presentaba sus proyectos, desarrolló un método de mostrar sus trabajos, por medio de vistas panorámicas 
desplegables en las que aprecia el antes y el después de los jardines (Fig. 6), incluso las versiones diurna y nocturna ${ }^{27}$. Pero Repton no solo realizó jardines y dibujos, ya que publicó tres manuales de jardinería paisajista, entre 1795 y 1816, que tuvieron una influencia real en Inglaterra y en todo el Continente ${ }^{28}$.

En la novela Mansfield Park (1814), de Jane Austen, hay un capítulo, el sexto, en el que un grupo de jóvenes discute sobre la conveniencia de que Mr. Repton mejore la finca de uno de ellos con motivo de su casamiento y la asunción de su nueva responsabilidad como cabeza de familia. Uno de los jóvenes, describe cómo Humphry Repton ha transformado la finca de otro amigo al que acaba de visitar de manera que "la casa ha cobrado una perspectiva sorprendente" 29 . Obviamente, una novela no puede ser tomada como una fuente fidedigna de lo que sucedía en la realidad, pero el que la discusión entre jóvenes sobre la necesidad de mejorar una finca siguiendo los patrones de la jardinería pintoresca sea el tema de todo un capítulo es síntoma de hasta que punto ese tema fue asimilado por la sociedad de gusto, aquella que adquiría y leía las novelas de Jane Austen, así como de la popularidad y posición que el jardinero Humphry Repton adquirió en esa sociedad.

En la segunda mitad del siglo XVIII la transformación del territorio se convirtió en algo más que una moda o una distracción rural, se convirtió en una de las artes mayores. Este arte cobró un nombre: jardinería paisajista y desde Inglaterra se extendió como tal arte a los países
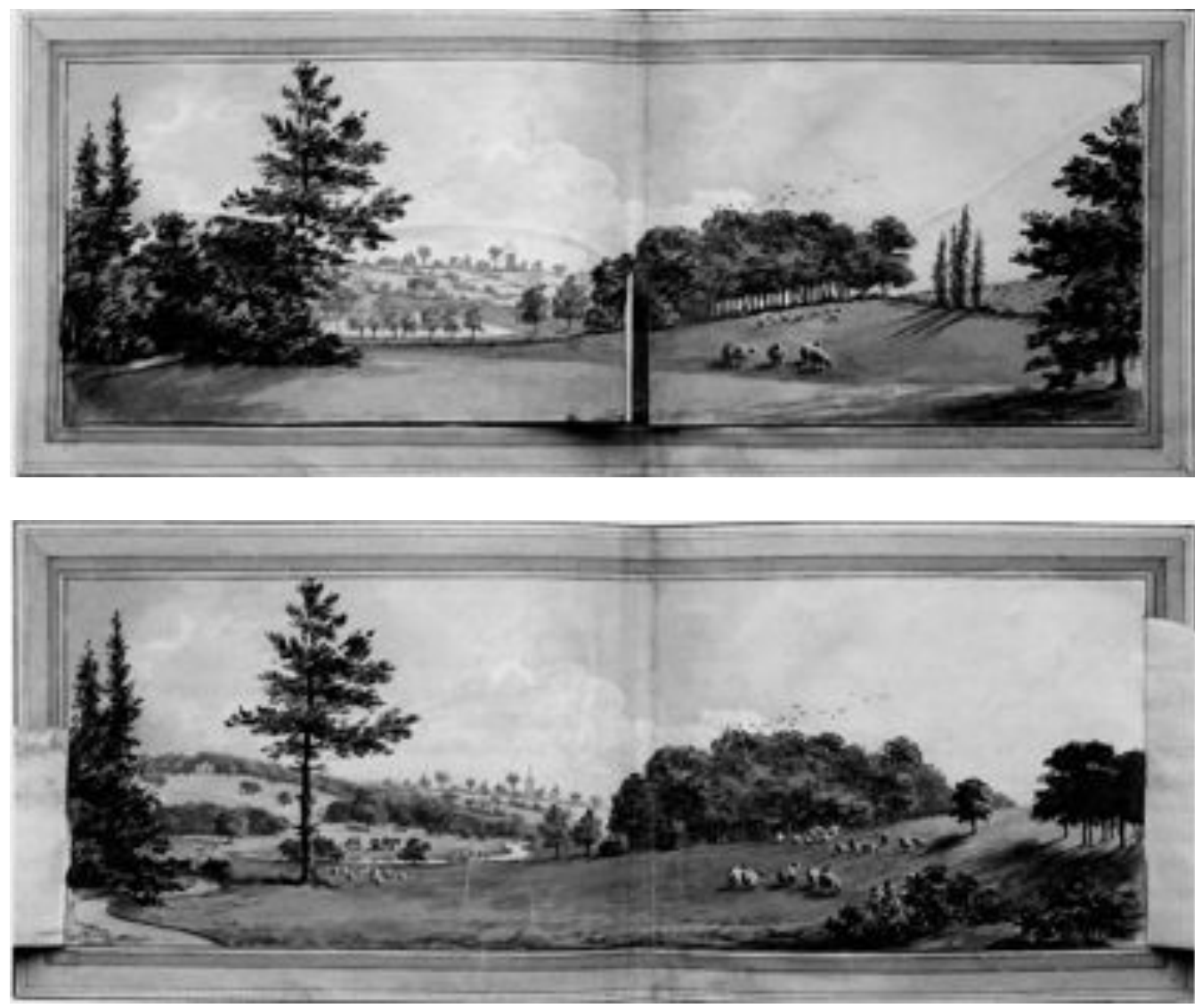

Fig. 6. Humphry Repton: Dos páginas de un Red book en las que se puede ver el antes y el después de un proyecto. 
nórdicos y Rusia, por un lado, y hacia los Estados Unidos, por otro. Al ser considerado arte, la jardinería paisajista desarrolló unas categorías estéticas, unos principios poéticos y unos preceptos teóricos que entretuvieron a filósofos, poetas y eruditos durante más de cien años, con un nivel de producción intelectual y editorial sorprendente. La identificación de la jardinería paisajista con Inglaterra es tal que en el resto de Europa se nombra como "jardín inglés" a cualquier combinación de praderas, pequeños lagos y grupos irregulares de árboles.

La categoría estética más característica fue, desde luego, lo pintoresco, teorizada por WiIliam Gilpin, Richard Payne Knight y Uvedale Price. Estos dos últimos: nobles terratenientes, viajeros del grand tour y coleccionistas de pintura de Claudio de Lorena y de Salvatore Rosa, se enzarzaron en una discusión de altos vuelos intelectuales a la vez que experimentaron sus teorías en sus propios territorios. Pero, para el terrateniente inglés el placer de lo estético no estaba reñido con la producción económica, antes bien, una finca que es productiva acentúa los placeres de su contemplación con las rentas que produce. De esta manera surgió el invento de la ferme ornée, que se le atribuye a Philip Southcote, quien mejoró su propiedad rural, Wooburn Farme ${ }^{30}$ (Fig. 7), incluyendo entre los prados dedicados a pastar el ganado escenas elíseas que estaban inspiradas en los jardines de William Kent. La invención del ha-ha ${ }^{31}$, atribuida al arquitecto John Vanbrugh, permitió que los animales de granja pudieran compartir el espacio del jardín paisajista con las actividades deportivas y sociales que se practicaban en sus praderas.

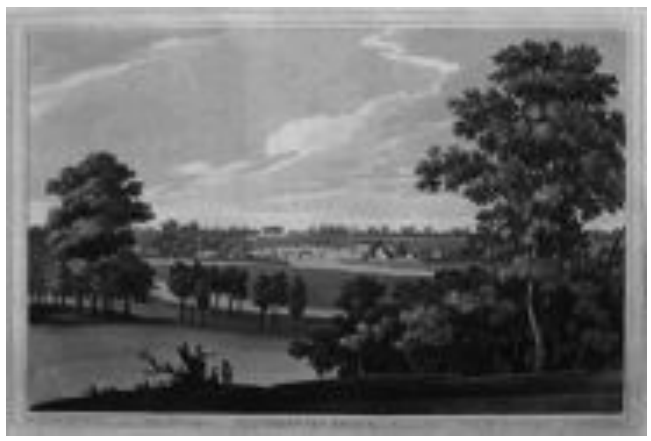

Fig. 7. Vista de Wooburn Farme. Dibujo de J. Farrington, grabado de J. C. Stadler, Londres, junio 1793.
Las teorías sobre lo pintoresco y las realizaciones más importantes que de ellas se destilaron abarcan en Gran Bretaña un periodo de unos cien años, que podemos situar entre 1730 y 1830. Entender lo pintoresco como un periodo de la historia del arte permite explicar no solo un estilo en jardinería o en pintura de paisaje sino toda la historia del arte inglés durante esa centuria, muy particularmente la arquitectura, que se hace difícilmente equiparable a la del resto del Continente. Lo pintoresco animó una de las obras mayores de esta historia de la arquitectura inglesa, Blenheim Palace (1705-1724), obra de John Vanbrugh y Nicholas Hawksmoor, palacio colosal que bajo ningún concepto puede ser interpretado como obra barroca, a pesar de sus complejos juegos volumétricos, ni presentarse como ejemplo del particular clasicismo inglés, ya que tampoco es un edificio clasicista, a pesar de apoyarse en un orden corintio principal y un orden dórico auxiliar (Fig. 8). John Summerson explica claramente que "comparado con la solemnidad del Louvre, Blenheim es pintoresco y movedizo" 32 .

Las ideas sobre lo pintoresco desarrolladas en poesía, pintura, novela y jardinería permitieron encontrar las cualidades de una arquitectura doméstica autóctona, que abarca todas las escalas, desde el gran conjunto palaciego hasta el pequeño cottage, y que ha permitido configurar la imagen de la Inglaterra rural a través de edificios aislados, de pequeñas villas, de la composición de pueblos y hasta de la extensión de ciudades. Una arquitectura que, dejando de lado los historicismos continentales, pero aprovechando algunos estilemas cultos, tomados de

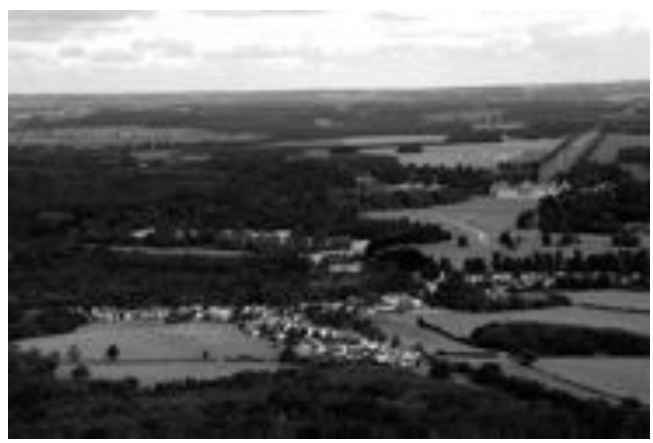

Fig. 8. Vista general de Blenheim Palace. 
diferentes épocas, se apoya en el movimiento de los volúmenes, en el contraste de formas desiguales, en las irregularidades de la composición y en los efectos de textura conseguidos con los materiales empleados, pero sobre todo que se caracteriza por integrarse en el paisaje, tanto por la pictórica elección de su emplazamiento y la adecuación con el entorno, como por la habilidad que algunos arquitectos consiguieron para que ese entorno pusiera en valor las cualidades de lo construido.

El mundo rural inglés no se construyó desde la necesidad de sus habitantes, agudizando el instinto de supervivencia para optimizar recursos escasos, sino desde la potencia económica de terratenientes que poseían grandes rentas y un buen gusto que manaba de una formación cultural basada en el conocimiento y la práctica de las artes (Fig. 9). Aquellos terratenientes no solo construyeron grandes mansiones, como Blenheim, que equiparon con bibliotecas, colec-

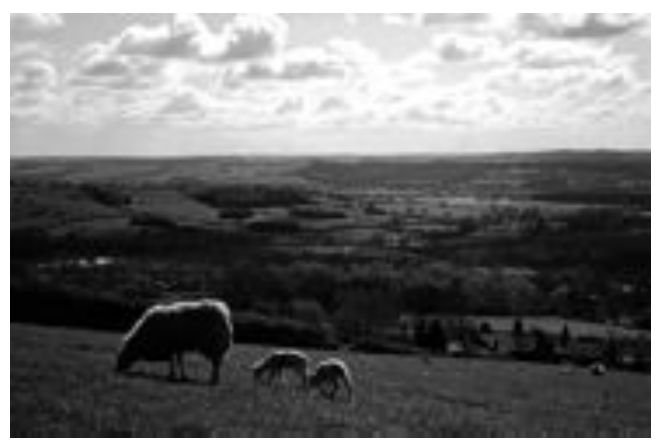

Fig. 9. Imagen de la Inglaterra rural. Jiri Hodan: English Landscape. ciones de maravillas y galerías de pinturas sino que desarrollaron una arquitectura menor que abarca desde el cottage, la rectoría y la iglesia parroquial hasta el desarrollo de la 'ciudad rural', premonición de la 'ciudad jardín', ideada por el arquitecto John Buonarroti Papworth y desarrollada en Chaltenham en la década de los años 1820, asentándose así lo que podríamos llamar los preceptos del urbanismo pintoresco.

Lo pintoresco, en tanto que categoría estética o como periodo historiográfico, se puede interpretar como producto de una voluntad anticlásica, actitud que pareció muy pertinente para la sensibilidad y el arte británicos en aquella época. Inglaterra, dominadora de un extenso imperio del que llegaban a la metrópoli variados objetos, imágenes e ideas desde lejanos lugares, y donde quedan innumerables restos de abadías y castillos en ruinas de un pasado medieval idealizado, fue el país idóneo para esa valoración positiva de lo que no es clásico, de aquello que se entendía como italiano o francés. Esta interpretación de lo pintoresco como periodo historiográfico del arte británico se la debemos al trabajo de un grupo de historiadores interesados en la interpretación del gusto pintoresco y sus consecuencias en la arquitectura y el jardín ingleses, entre los que se encuentran personajes como Christopher Hussey (1899-1970), Sir John Summerson (1904-1992), Dorothy Nancy Stroud (1910-1997), Nikolaus Pevsner (1902-1983) y John Steegman (1899-1966)33, pero el análisis del trabajo de estos historiadores escapa ya al tema de la mirada pintoresca planteado en este ensayo. 


\section{NOTAS}

1 Malcolm Andrews, The Search for the Picturesque, Scolar Press, Aldershot, 1989, 1990². Sidney K. Robinson, Inquiry into the Picturesque, The University of Chicago Press, Chicago, 1991. John Dixon Hunt, Gardens and the Picturesque. Studies in the History of Landscape Architecture, The MIT Press, Cambridge (Mass), 1992. Javier Maderuelo, Nuevas visiones de lo pintoresco: el paisaje como arte, Fundación César Manrique, Teguise, 1996. John Dixon Hunt, The Picturesque Garden in Europe, Thames \& Hudson, Londres, 2002, 2004². Javier Maderuelo, "La teoría de lo pintoresco y la obra de William Gilpin", en William Gilpin, Tres ensayos sobre la belleza pintoresca, Abada, Madrid, 2004. Iñaki Ábalos, Atlas pintoresco. Vol.1: El observatorio. Vol. 2: Los viajes, Gustavo Gili, BarceIona, 2005. Iñaki Ábalos (ed.), Naturaleza y artificio. El ideal pintoresco en la arquitectura y el paisajismo contemporáneos, Gustavo Gili, Barcelona, 2009. Christopher Hussey, Lo pintoresco, Biblioteca Nueva, Madrid, 2013 (1 ${ }^{\text {a }}$ ed. en inglés, 1927).

2 Los historiadores de la filosofía suelen ubicar esquemáticamente esta escuela inglesa en el movimiento más amplio de la llustración, oponiéndola al "racionalismo continental".

${ }^{3}$ Sirva como ejemplo el ensayo de David Hume Of the Standard of Taste. David Hume, La norma del gusto (1757), Revista Teorema, Valencia, 1980. (ed. José García Roca).

${ }^{4}$ Leon Battista Alberti, Sobre la pintura, Fernando Torres, Valencia, 1976, p. 146.

${ }^{5}$ Véase: Leonardo da Vinci, Tratado de pintura (ed. Ángel González García), Editora Nacional, Madrid, 19834, pp. 45-66.

${ }^{6}$ Sirva como ejemplo el tratado de retórica Peri Hypsous, atribuido en un principio a Dionysius Cassius Longino (epicúreo griego S. I d. de JC.), que fue descubierto en el siglo XVI y editado en griego en Basilea en 1554. Este libro fue traducido al francés por Nicolas Boileau-Despréaux en 1674 con el título Traité du sublime ou du merveilleux dans le discours.

7 San Ignacio de Loyola fue beatificado en 1609, Santa Teresa de Jesús en 1614, San Felipe Neri en 1615 y San
Francisco Javier en 1619. San Carlos Borromeo fue canonizado santo en 1610 y los nuevos cuatro beatos lo fueron el mismo día, el 22 de mayo de 1622. Todos estos nuevos santos reclamaron un enorme despliegue iconográfico en el que participaron los más importantes artistas del barroco.

${ }^{8}$ Me refiero a Nicolas y Gaspard Duguet, quien firmaba Poussin por ser cuñado de este. En muchos casos los ingleses de los siglos XVIII y XIX confunden a ambos pintores bajo un único nombre: Poussin.

9 James Thomson (1700-1748), autor de The Seasons (1726-1730) John Dyer (1699-1757), autor de Grongar Hill (1726); Thomas Gray (1716-1771) autor de Elegy Written in a Country Churchyard, (1751); William Shenstone (1714-1763), autor de The judgement of Hercules, (1740).

${ }^{10}$ Hussey los caracteriza como "poetas de lo pintoresco". Christopher Hussey, Lo pintoresco, op. cit., p. 145.

11 Ibíd., p. 145

12 El jardín existe aún en Halesowen, West Midlands, cerca de Birmingham, y se puede visitar.

${ }^{13}$ Citado por Christopher Hussey, op. cit., p. 184.

14 Richard Graves, Columella, Or, The Distressed Anchoret: A Colloquial Tale (1779), Presses Universitaires du Mirail, Toulouse, 1989. Edición a cargo de Cassilde Tournebize, que hace un análisis de la obra en francés.

${ }^{15}$ William Mason, clérigo de Yorkshire, en su poema satírico, en cuatro cantos, titulado The English Garden, publicado en 1781 (traducción al francés, 1788)

${ }^{16}$ Edmund Burke, A Philosophical Inquiry into the Origin of our Ideas of the Sublime and Beautiful (1757). Existen dos versiones en español: Indagación filosófica sobre el origen de nuestras ideas acerca de lo bello y lo sublime, Colegio Oficial de Aparejadores y Arquitectos técnicos, Murcia, 1985, con una traducción de Juan de la Dehesa (1807); e Indagación filosófica sobre el origen de nuestras ideas acerca de lo sublime y lo bello, Técnos, Madrid, 1987, con una traducción moderna de Menene Gras Balaguer

17 A pesar de que disfrutó de numerosas ediciones hasta 1801 , no existe ninguna reciente.
18 William Gilpin, Three Essays on picturesque beauty, on picturesque travel and on sketching landscape, to which is added a Poem on Landscape Painting, Londres, 1792. Vease: GILPIN William, Tres ensayos sobre la belleza pintoresca, op. cit.

${ }_{19}$ Uvedale Price, Essays on the Picturesque, as compared with the sublime and Beautiful (3 vols.), Londres, 1794, $1810^{2}$. Hay ed. facsímil de la $2^{\text {a }}$ en: Greeg International, Farnborough, 1971.. vol. I, págs. 40 y ss.

${ }^{20}$ Richard Payne Knight, The Landscape a Didactical Poem, Londres, 1794, $1795^{2}$. Hay ed. facsímil de la $2^{\text {a }}$ en: Greeg International, Farnborough, 1972.

${ }^{21}$ Sobre la controversia entre Price, Knight y Repton véase: Walter John Hipple, The Beautiful, the Sublime, and the Picturesque in Eighteenth-Century British Aesthetic Theory, The Southern University Press, Carbondale, (III.), 1957, págs. 224-283.

22 Uvedale Price replicó al Didactical Poem de Knight, que estaba dedicado a él, con la publicación de $A$ Dialogue on the distinct Characters of the Picturesque and the Beautiful, Hereford, 1801, al que contestó Richard Payne Knight con: An Analytical Inquiry into the Principles of Taste, Londres, 1805, $1808^{4}$

${ }^{23}$ La agrupación de árboles en bloques macizos, muy característicos del trabajo de Brown, reciben el nombre de crumps.

${ }^{24}$ Sobre la vida y la obra de Brown, véase Dorothy Stroud, Capability Brown, Country Life, Londres, 1950, reed. Faber \& Faber, Londres, 1984.

25 Joseph Addison, Spectator, $n^{\circ}$. 141, 1712, citado por Christopher Hussey, op. cit., nota 1, p. 182.

${ }^{26}$ Christopher Hussey, op. cit., p. 182.

27 Repton publicó una selección de proyectos de sus Red books en forma de libro con comentarios, ilustraciones y encartes, bajo el título Sketches ant Hints on Landscape Gardening, Londres, 1794

28 Sketches and Hints on Landscape Gardening (1795), Observations on the Theory and Practice of Landscape Gardening (1803), y Fragments on the Theory and Practice of Landscape Gardening (1816). 
29 Jane Austen, Mansfield Park, Random House Mondadori, Barcelona, $2010^{4}$, p. 66

${ }^{30}$ Wooburn Farm (hoy Woburn, con una sola o) se encuentra situada cerca de Addlestone, en el condado de Surrey. El término "ferme ornée" fue utilizado por primera vez por Stephen Switzer en Ichnographia Rustica (1718, reed. 1741-2)

${ }^{31}$ Ha-ha es un término propio del diseño de jardines con el que se nombra un tipo de zanja que está formada, en uno de sus lados, por un muro que queda oculto a la vista. El artificio se construye para impedir la entrada del ganado y permitir las vistas sin obstáculos desde el interior del jardín.
32 John Summerson, El lenguaje clásico de la arquitectura. De L. B. Alberti a Le Corbusier, Gustavo Gili, Barcelona, 1978, p. 127. ( $1^{\text {a }}$ ed. en inglés, 1963).

33 Se relacionan a continuación algunas de sus obras más significativas: Christopher Hussey, Lo pintoresco (1927), op. cit., English Gardens and Landscapes 1700-1750, Country Life, Londres, 1967; John Summerson, Architecture in Britain 1530-1830, Penguin, Londres, 1953; The Architecture of the Eighteenth Century, Thames \& Hudson, Londres, 1980; Dorothy Stroud, Capability Brown, Country Life, Londres, 1950, reed. Faber \& Faber, Lon- dres, 1984; Nikolaus Pevsner, From Manierism to Romanticism, Vol I de Studies in Art, Architecture and Design, Walker, Nueva York, 1968; John Steegman, The Rule of Taste from George I to George IV, Macmillan, Londres, 1936, reed. Century Hutchinson/The National Trust, Londres, 1986;

Consort of Taste 1830-1870, Sidgwick \& Jackson, Londres, 1950 ; -

Victorian taste: A Study of the Arts and Architecture from 1830 to 1870 , Nelson, Londres, 1970 (con prólogo de Nikolaus Pevsner), reed. Ebury Press, Londres, 1987. 